\title{
Molecular pathogenesis of emphysema
}

\author{
Laimute Taraseviciene-Stewart and Norbert F. Voelkel
}

Pulmonary and Critical Care Medicine Division, University of Colorado Health Sciences Center, Denver, Colorado, USA.

\begin{abstract}
Emphysema is one manifestation of a group of chronic, obstructive, and frequently progressive destructive lung diseases. Cigarette smoking and air pollution are the main causes of emphysema in humans, and cigarette smoking causes emphysema in rodents. This review examines the concept of a homeostatically active lung structure maintenance program that, when attacked by proteases and oxidants, leads to the loss of alveolar septal cells and airspace enlargement. Inflammatory and noninflammatory mechanisms of disease pathogenesis, as well as the role of the innate and adaptive immune systems, are being explored in genetically altered animals and in exposure models of this disease. These recent scientific advances support a model whereby alveolar destruction resulting from a coalescence of mechanical forces, such as hyperinflation, and more recently recognized cellular and molecular events, including apoptosis, cellular senescence, and failed lung tissue repair, produces the clinically recognized syndrome of emphysema.
\end{abstract}

\begin{abstract}
. . animals have really two environments: a milieu exterieur in which the organism is situated and a milieu interieur in which the tissue elements live. - All the vital mechanisms, varied as they are, have only one object: that of preserving constant the conditions of life in the milien interieur.
\end{abstract}

-Claude Bernard (1)

Emphysema is defined as airspace enlargement of the adult lung (2) (Figures 1 and 2), in contrast to developmentally impaired alveolarization of the neonatal lung. Human emphysema was originally described by Ruysch in Amsterdam at the end of the 17 th century and in the 19 th century by the French physician Laennec (3), who noted "marked variations in the size of the air vesicles, which might be smaller than a millet seed or as large as a cherry stone or haricot. Vesicles of the latter size were produced by the coalescence of adjacent air spaces following rupture of the alveolar walls" (4).

Emphysema most frequently develops between the ages of 45 and 60 as a component of chronic obstructive pulmonary disease (COPD) in smokers (5), but emphysematous lung destruction has also been reported in other non-smoking-related disorders such as HIV-1 infection (6) or hypersensitivity pneumonitis (7). The clinical syndrome of COPD includes both pulmonary manifestations, including airflow obstruction, small airway inflammation (bronchiolitis), and lung parenchyma (alveolar) destruction (8); and extrapulmonary manifestations, including muscle wasting, osteoporosis, and anemia (9-11). Although sputum production and cough are frequent symptoms, the most disabling aspect of severe COPD is breathlessness (dyspnea). The present treatment of COPD consists of daily administration of inhaled bronchodilators and/or steroids and oxygen supplementation, often continuously for 24 hours for hypoxemic patients (12); there is no emphysema-specific treatment. Mortality and morbidity from COPD is an increasingly serious global health problem; COPD ranked sixth among the causes of death globally in 1990 but is expected to be the third most common cause of death in 2020 (13). In addition, the health care costs of COPD are considerable (14).

Nonstandard abbreviations used: AAT, $\alpha_{1}$-antitrypsin; COPD, chronic obstructive pulmonary disease.

Conflict of interest: The authors have declared that no conflict of interest exists. Citation for this article: J. Clin. Invest. 118:394-402 (2008). doi:10.1172/JCI31811.

\section{A smoking gun?}

The question of whether cigarette smoking is a cause of emphysema was raised in the 1950s (15), and the landmark study by the British epidemiologists Fletcher and Peto supported the concept that chronic cigarette smoking is indeed the major cause of chronic bronchitis and emphysema (16). More recently, a consensus has begun building that the lung structure is attacked and destroyed by inhaled noxious agents contained in cigarette smoke or in polluted air; the effects of exposure to diesel exhaust, ozone, and microparticles are being examined (17-19). There is also agreement that not every long-term heavy smoker develops emphysema - the painter Pablo Picasso, who started smoking as a teenager but remained active and productive beyond his ninetieth year, comes to mind - and that genetic susceptibility factors underlie emphysema development (20). One alternative concept of emphysema pathogenesis is that the disease is a manifestation of premature aging of the lung; gene polymorphisms are being investigated, and researchers are searching for candidate genes that encode proteins that are components of inflammatory pathways (21), antioxidants, and proteolysis inhibitors $(20,22,23)$. Many aspects of the pathobiology of human emphysema remain unclear. For example, it has been recognized for many years that human emphysema can affect the entire lung or have a predilection for the upper lobes and subpleural areas. The reasons for these regional differences in emphysema distribution are not understood (23). Evidence of both emphysema and pulmonary fibrosis in the same patient has been reported, implicating some common pathways leading to the different outcomes $(24,25)$. It remains likewise unresolved why emphysematous lung destruction is relentlessly progressive in some patients even many years after smoking cessation.

The destruction of alveolar-capillary (epithelial and endothelial) cells by proteolytic enzymes has been generally accepted as one of the principle mechanisms of destructive airspace enlargement (Figure 3), based on the demonstration that intratracheal instillation of the cysteine protease papain (a meat tenderizer) caused emphysema in rats (26) and on an association between emphysema and a genetic deficiency in the neutrophil elastase inhibitor $\alpha_{1}$-antitrypsin (AAT) (27). Whereas a large number of animal studies, which make use of spontaneous or engineered genetic variations, support the inflammation-proteolysis theory, some studies have raised questions about whether inflammatory mechanisms are sufficient or necessary to explain airspace enlargement per se, and other pathogenetic mechanisms of this 


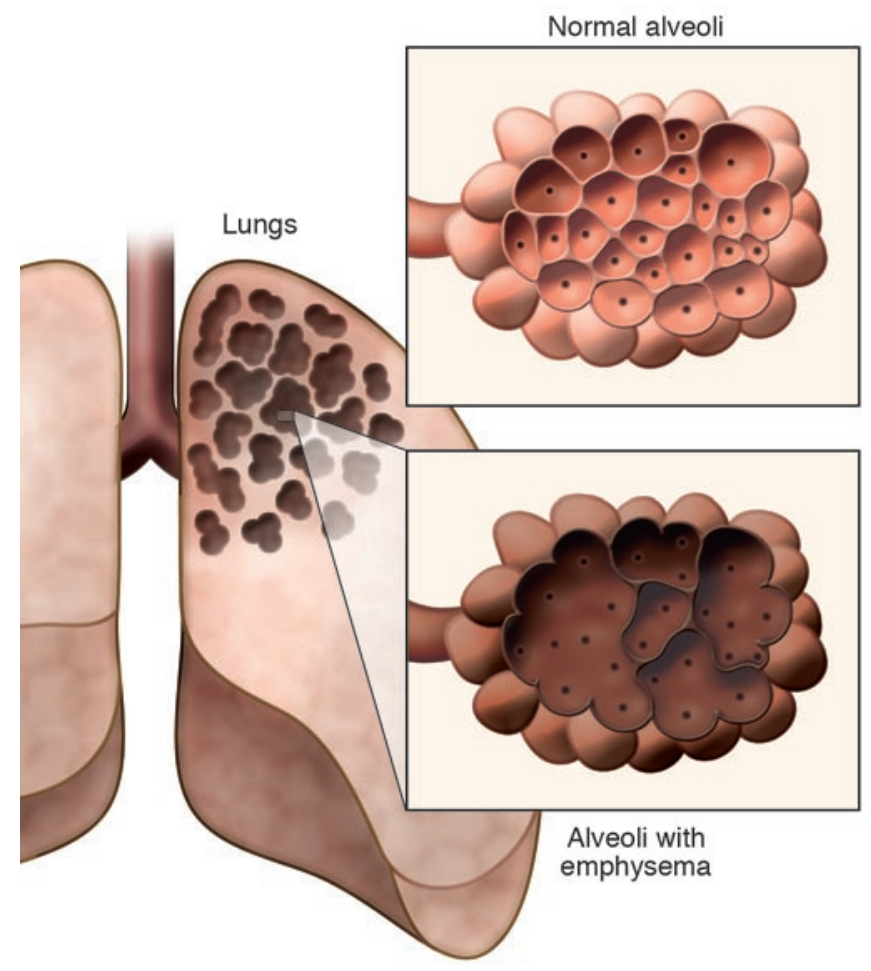

Figure 1

Normal versus emphysematous alveoli.

disease are being considered (28-31) (see Adaptive immunity in emphysema). Although emphysema is only part of the radiographic and histological presentation of COPD, this review focuses on alveolar septum destruction and airspace enlargement and will highlight a number of different pathogenetic mechanisms that can be understood to operate individually or in concert. We also attempt to integrate the increasingly large - and growing - number of molecular targets that have been experimentally investigated and shown to cause airspace enlargement. For further information, we refer the reader to recent comprehensive reviews on the pathogenesis of emphysema $(32,33)$.

\section{Adult lung structure maintenance program}

The lung, like the skin and the gut, has a large surface area that is constantly exposed to the environment and is also a metabolically active organ with a large blood-air interface designed for both gas exchange and capillary endothelial cell processing of a myriad of endogenous substances. This dual function of gas exchange and metabolism can only be maintained throughout adult life if the structure of the organ is homeostatically maintained and defended against the external and internal environment. A mod-

\section{Figure 2}

Human emphysema. (A) Chest CT scan of a 56-year-old man with COPD demonstrating a profound loss of the lung parenchyma and paucity of lung vessels. (B) Whole-lung section demonstrating ubiquitous "holes," i.e., emphysema. (C) Histology of end-stage emphysematous lung. H\&E staining; magnification, $\times 40$. The loss of alveolar septal cells is not accompanied (in this specimen) by significant inflammatory cell accumulation. ern concept is that both resident and bone marrow-derived stem cells participate in the maintenance of the adult lung structure. Our knowledge of lung cell turnover and dependence on extrapulmonary repair mechanisms at present is rudimentary. However, it is conceivable that a program of lung structure maintenance of critical importance during lung development has retained and preserved architectural building principles and that, later in life, elements of this developmental program are utilized to protect the lung against destruction, antioxidants, antiproteases, and attack by the innate immune system. Furthermore, it is possible that destruction of the lung parenchyma may result if there is chronic unopposed oxidant stress, unopposed proteolysis, apoptosis, and impaired clearance of apoptosed cell bodies (34-37), cellular senescence without adequate cell replacement $(38,39)$, or a switch from an innate toward an autoimmune response (40).

\section{Pathology of human emphysema}

As stated above, the pathology of COPD relates to inflammatory changes in the small airways and to the loss of alveolar septal structures and small vessels (41). The alveolar septae are infiltrated by neutrophils, clusters of $\mathrm{CD} 68^{+}$macrophages, and lymphocytes. A recent study by Hogg et al. (42) provided a quantitative cellular analysis of lung tissue samples from patients with COPD of all degrees of severity and lung function impairment. The presence of lymph follicles in the parenchyma or dendritic cell infiltration and Th1 cells was noted, raising questions about the nature of the immune response and its potential role in emphysematous destruction. One contemporary pathogenetic model of emphysema has been built on the data provided by many laboratories (Figure 3). This model posits that neutrophil elastase and MMP-12 released by activated macrophages enzymatically destroy the elastin scaffold of the alveolar spaces. However, the production of proteases is not restricted to inflammatory cells; structural cells such as epithelial and endothelial cells are also capable of produc-
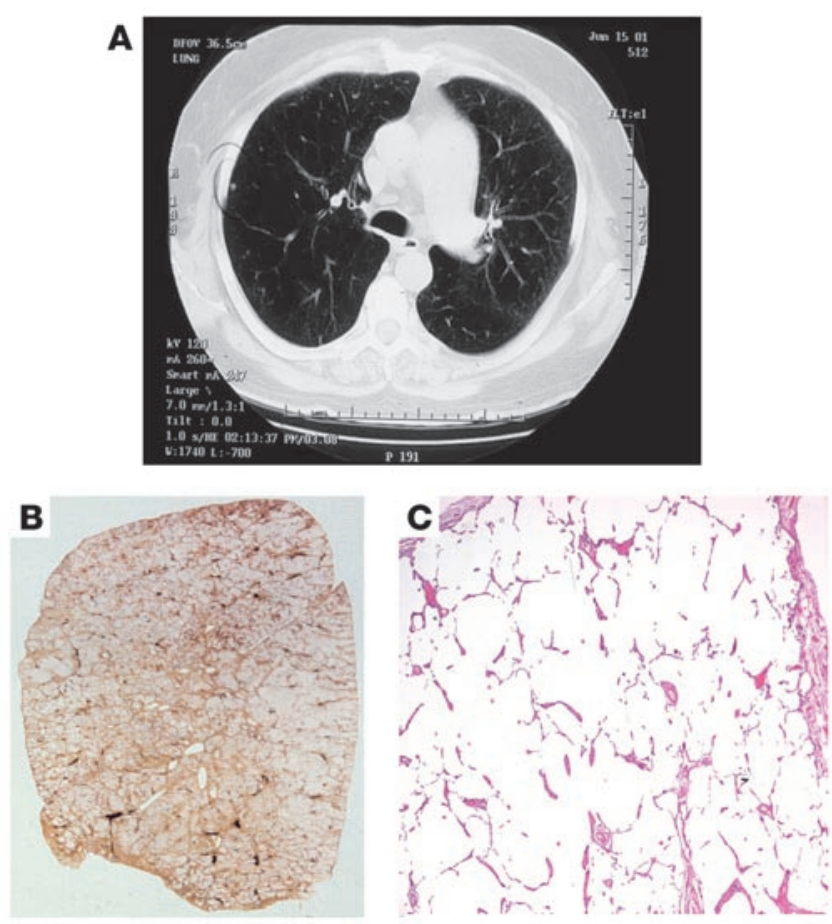


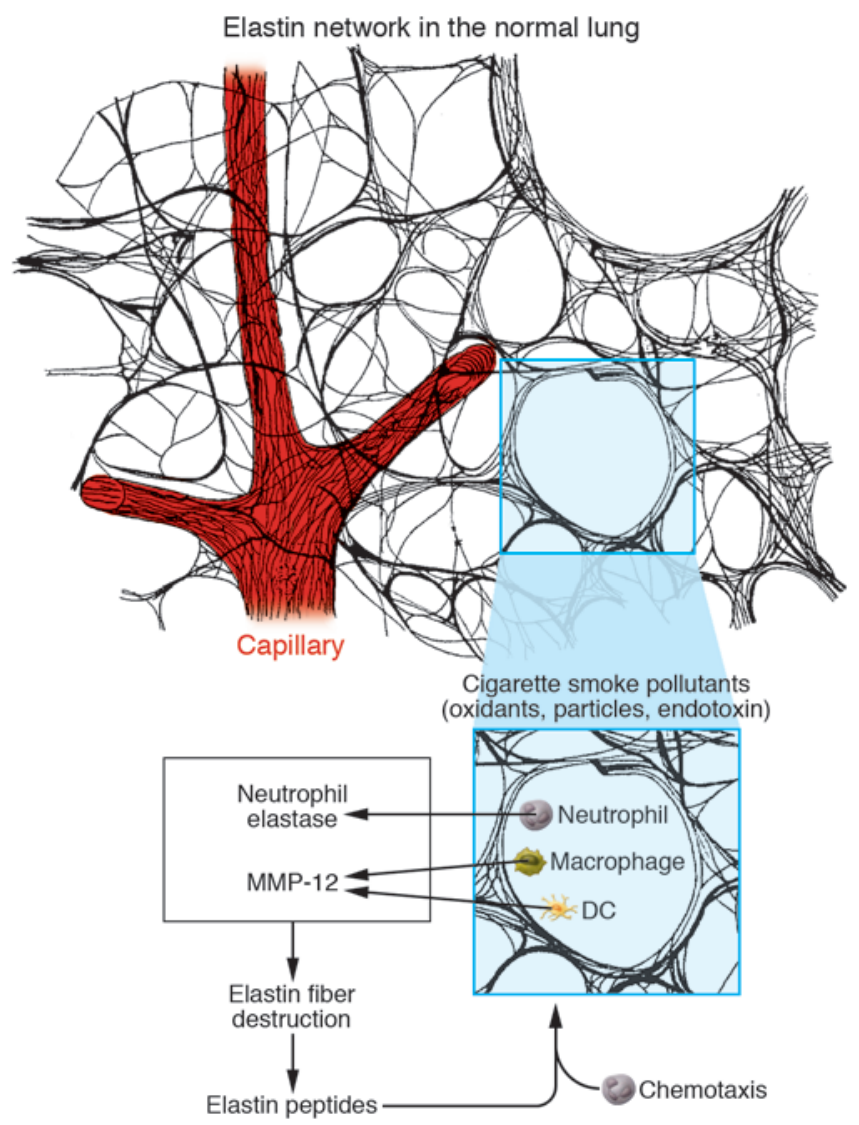

ing proteases $(43,44)$. Elastin fragments in turn are chemotactic (45) and attract inflammatory cells to sites of injury, thus suggesting a joint role of inflammatory cells and proteases. Strong experimental support of this concept is provided by data showing that elimination of alveolar macrophages in rats (46) and knockout of MMP-12 in mice (47) protected these animals against cigarette smoke-induced emphysema.

Although the presence of inflammatory cells that can release oxidants and proteases has now been well documented, one is reminded that a number of acute lung diseases that manifest with massive inflammation (such as bacterial pneumonia and acute lung injury) develop and resolve entirely without emphysematous parenchyma destruction. Figure $2 \mathrm{C}$ shows a section of a human lung with severe airspace destruction - yet inflammatory cells are absent; this does not imply that inflammatory cells were not present earlier or that lung structural cells secrete destructive proteases.

\section{Animal models of emphysema}

Can animal models help us to resolve the issue of whether inflammation is necessary in emphysema pathogenesis? Inflammation is defined as the presence of inflammatory cells and altered levels of mediators of inflammation in the parenchyma. Rodent emphysema models can perhaps be broadly categorized as: (a) genetic models, which via the use of gene manipulations such as gene overexpression or knockout, can be utilized to identify the usually silent and hidden actions of elements of the lung structure maintenance program; and (b) exposure models, which involve inducing damage to the adult lung of wild-type or transgenic animals (Tables 1 and 2) and explore the mechanisms of cellular

\section{Figure 3}

Proteolytic destruction of the elastin fiber network by cigarette smoke-activated inflammatory cells. This schematic illustrates the dense elastin fiber network in the lung; the elastin fibers form a particularly dense network around lung capillaries. Neutrophils, macrophages, and dendritic cells have been recognized as producers of proteases. In addition to neutrophil elastase and MMP-12, there have been a myriad of proteases identified in human and animal emphysema that can degrade elastin, collagen, and fibronectin. Loss of the alveolar septal scaffold after enzymatic degradation of various matrix proteins causes airspace enlargement. Elastin peptides are chemotactic and can attract additional inflammatory cells into the lung, thus generating a vicious cycle.

damage and protection. Many of the recently developed experimental models of emphysema - smoking-related or not - show that inflammatory cells of varying compositions populate the airspaces in increased numbers $(48,49)$.

Yeast, worm, fly, and mouse molecular genetic analysis and engineering allow us to dissect elementary biological mechanisms, but in the long run it may be unproductive to assume that all the important problems of human lung pathobiology can be solved in the mouse, for at least four different reasons. The mouse lung has no systemic pressure bronchial circulation; the mouse likely does not possess many of the cytochrome P450 genes that govern human toxicology; and there are many important differences in the function of the immune systems of mice and humans. Last, rodents may have - and may use - the option of perpetual lung growth.

\section{Proteases and AAT}

Proteases can enzymatically degrade a variety of lung matrix proteins, and antiproteases protect against their degradation. The topic of proteases and antiproteases and their roles in various emphysema models has recently been reviewed (50). As the number of reported elastases, MMPs, cathepsins, and known actions of caspases (51) is steadily increasing, it becomes apparent that the structure maintenance program must function with both proteases and antiproteases (reviewed in refs. 52, 53). The activity of inflammatory cell-released proteases is inhibited by antiproteases, while other proteases in alveolar septal structure cells are engaged in the ongoing work of repair and angiogenic remodeling and join the neutrophil and macrophage elastases in support of the innate immune response. Although Figure 3 schematically depicts an elastin-based aspect of lung tissue destruction, a large number of reports have also emphasized a role of collagenases and described collagen breakdown in emphysema and emphysema models (54-58). Other known factors such as breakdown of hyaluronan by reactive oxygen species can also contribute to the inflammatory effects, while aerosolized hyaluronan prevents airspace enlargement in a mouse model of cigarette smoke-induced pulmonary emphysema (Table 2 ). The fact that a null mutation of the gene encoding the elastolytic cysteine cathepsin S-protected mice against IFN- $\gamma$-induced emphysema (59) illustrates how complex potentially proteolytic lung destruction may be, particularly given the large number of enzymes as well as their targets - many structural proteins. For example, cathepsin $\mathrm{S}$ affects the production of type IV collagen-derived antiangiogenic peptides (60). Many questions remain unanswered. One fundamental question relates to the functional and temporal interactions among 


\section{Table 1}

Genes involved in airspace enlargement in mouse models of emphysema

\begin{tabular}{|c|c|c|}
\hline Gene & Result & Ref. \\
\hline \multicolumn{3}{|l|}{ Overexpression model } \\
\hline Interleukin 1b (//1b) & Inflammation, fibrosis & S22, S23 \\
\hline Interleukin 4 (I/4) & Eosinophilic infiltration, fibrosis & 87 \\
\hline Interleukin 13 (//13) & Inflammation & S24 \\
\hline Interferon $\gamma($ Ifng $)$ & Inflammation & S25 \\
\hline Tumor necrosis factor- $\alpha$ (Tnfa) & Chronic inflammation & 68 \\
\hline \multicolumn{3}{|l|}{ Knockout model } \\
\hline Vegf conditional KO & Absence of inflammation & 102 \\
\hline Surfactant-associated protein D (Sftpd) & Foamy macrophages & S26 \\
\hline Toll-like receptor 4 (TIr4) & Increased oxidant generation and elastolytic activity & 31 \\
\hline Tissue inhibitor of metalloproteinase 3 (Timp3) & Spontaneous progressive air space enlargement & S27 \\
\hline Fibroblast growth factor 23 (Fgf23) & Premature aging-like phenotype & S28 \\
\hline$\beta_{6}$ subunit of $\alpha_{v} \beta_{6}$ integrin & Age-dependent emphysema & S29 \\
\hline Smad3 & Age-related emphysema & $\mathrm{S} 30, \mathrm{~S} 31$ \\
\hline Klotho & Imbalance of MMP-9 and TIMP-1 & S32, S33 \\
\hline Signal transducer and activation of transcription (Stat3) & High susceptibility to viral infection & S34 \\
\hline
\end{tabular}

proteolysis, oxidant stress, and caspase-dependent and -independent apoptosis in the epithelial cells, endothelial cells, and macrophages of the alveolar spaces. For example, in a rodent model of emphysema, broad-spectrum caspase and MMP inhibitors and antioxidants $(36,61,62)$, as well as AAT, $(63)$ inhibit apoptosis, suggesting that some powerful, perhaps mutually enhancing interactions between products of proteolysis (cleaved protein fragments?) and oxidant stress culminate in endothelial and epithelial cell death (64). Since AAT can stop the vicious cycle of oxidant stress/proteolysis/apoptosis, and protect against experimental emphysema in rodents (65), Tuder's group explored whether this usually very abundant plasma protein inhibits caspase activation. Indeed, AAT induced the inhibition of caspases, which was associated with reduced oxidant stress in vivo and also in cultured endothelial cells (66). Again, a new concept is emerging: that AAT has additional actions (67) that are clearly unrelated to its wellstudied enzymatic antineutrophil elastase activity and that it protects endothelial cells against oxidants.

\section{Innate immunity and oxidative stress}

Innate immunity relies on pattern recognition receptors that recognize molecular structures common to many microorganisms, such as LPS and endogenous ligands such as heat shock proteins. Activation of TLR4 by LPS triggers production of both cytokines and reactive oxidant species. Alterations of lung cytokines, oxidant stress, and TLR signaling have all been associated with experimental emphysema. For example, lung-specific overexpression of TNF- $\alpha$ in mice causes emphysema and some degree of pulmonary hypertension (68). Knockout of the antioxidant transcription factor nuclear erythroid-related factor 2 (Nrf-2), which among other genes regulates the expression of glutathione peroxidase 2 (69), made mice susceptible to cigarette smoke exposure; they developed airspace enlargement as well as more pronounced inflammation and apoptosis of alveolar septal epithelial and endothelial cells (70). In a manner analogous to the way in which elimination of an important antioxidant "switchboard" upsets the lung cell oxidant/antioxidant balance, alterations of the TLR system may change the interactions of the lung with the milien exterieur. Zhang et al. (31) followed TLR4-knockout mice (Tlr4-/- mice) into middle age and found that the animals spontaneously developed emphysema associated with an oxidant/antioxidant imbalance due to increased Nox3 (a novel NADPH oxidase) gene expression and elastin degradation. Interestingly, the elastin breakdown was caused by oxidants, since NADPH oxidoreductase inhibition prevented the elastin breakdown. Also of interest, the $\mathrm{Tlr}^{-/-}$mice did not show infiltration of the lung parenchyma with inflammatory cells, and the authors speculate that the source of oxidants and of proteolytic activity may be the alveolar septal endothelial cells. A new concept has thus emerged: there may be a "TLR4 tone" (and perhaps a more general "TLR tone") that provides a low-grade activation of the innate immune system that is required for dayto-day lung structure stability. This would make TLR4 an integral element of the lung structure maintenance program (71) by contributing to the defense of endothelial cells against oxidants and also via Th2 cell activation (72). Other soluble innate host defense molecules such as surfactant protein $\mathrm{D}$ are associated with regulation of local lung inflammatory milieu, and the knockout mice develop emphysema (Table 1).

Sphingolipids have recently received attention since Petrache et al. (73) found elevated levels of long-chain ceramides in human emphysematous lungs, increased ceramide levels in the VEGFR blockade rat emphysema model, and inhibition of apoptosis and emphysema after the use of neutralizing anticeramide antibodies. In contrast to the proapoptotic ceramides, sphingosine- 1 phosphate may, in such a scenario, serve as a balancing prosurvival factor.

\section{Adaptive immunity in emphysema}

Finally, there may be additional mechanisms at play in the slow, progressive destruction of the lung parenchyma, which can continue for decades after smoking cessation. What sustains the chronic inflammation for years after smoking cessation continues to puzzle investigators. Chronic, poorly controlled asthma in humans is associated with lung remodeling and a transition to fixed air- 


\section{Table 2}

Rodent models of emphysema

\begin{tabular}{|c|c|c|c|}
\hline Species & Trigger & Result & Ref. \\
\hline Guinea pig & Cigarette smoke & Emphysema and vascular remodeling & $98, S 14$ \\
\hline Rat & Cigarette smoke & Protected by simvastatin & S18 \\
\hline Rat & VEGFR blockade & $\begin{array}{l}\text { Protected by caspase inhibitor, } \\
\text { protease inhibitor, antioxidants }\end{array}$ & $36,61-63$ \\
\hline Rat & HUVEC injection & $\begin{array}{l}\text { Both antibodies and CD4+ } \mathrm{T} \text { cells } \\
\text { can transfer the disease }\end{array}$ & 40,44 \\
\hline Mouse & Neutrophil elastase & Protected by protease inhibitor & S35 \\
\hline Mouse & Cigarette smoke & $\begin{array}{l}\text { Protected by AAT and by } \\
\text { aerosolized hyaluronan }\end{array}$ & S36, S37 \\
\hline Mouse & Macrophage elastase (MMP-12) & $\begin{array}{l}\text { Protected against cigarette smoke- } \\
\text { induced emphysema }\end{array}$ & 47 \\
\hline $\begin{array}{l}\text { Mouse, Nuclear erythroid } 2 \\
\quad \text { p45-related factor } 2 \text { (Nfr2) K }\end{array}$ & Cigarette smoke, elastase instillation & Enhanced emphysema & S38, S39 \\
\hline $\begin{array}{l}\text { Mouse, CuZn superoxide } \\
\text { dismutase (CuZnSOD) overexpression }\end{array}$ & Cigarette smoke & Protected against emphysema & S40 \\
\hline Mouse, hemeoxygenase 1 overexpression & Cigarette smoke & Protected against emphysema & S41 \\
\hline Mouse, TNF $\alpha$ receptor (TNF $\alpha$ R) KO & Cigarette smoke & Protected against emphysema & $\mathrm{S} 42, \mathrm{~S} 43$ \\
\hline $\begin{array}{l}\text { Mouse, senescence marker } \\
\text { protein-30 (SMP-30) KO }\end{array}$ & Cigarette smoke & $\begin{array}{l}\text { Protected against oxidative stress } \\
\text { associated with aging and smoking }\end{array}$ & 111 \\
\hline Mouse & Caspase-3 instillation & Alveolar wall destruction & 29 \\
\hline Mouse & Cigarette smoke & $\begin{array}{l}\text { Protected by phosphodiesterase } 4 \\
\text { (PDE-4) inhibitor Roflumilast }\end{array}$ & S13 \\
\hline
\end{tabular}

way obstruction. Whether or how this fixed airway destruction relates to alveolar destruction is unclear. Whereas allergic asthma is understood to be an immune disorder wherein the antigen is sometimes known, and animal models of asthma - developed using a variety of immunization strategies - can be dissected to uncover multiple layers of the adaptive immune response, emphysema until recently has, as discussed, been seen as a problem of proteolysis, not of adaptive immunity. While this is somewhat perplexing because the burning cigarette can be seen as an antigen delivery device, most recently a concept of emphysema pathogenesis based on immune mechanisms has begun to emerge. A few elements of this concept are discussed here. Lung gene expression profiling of cigarette smoke-exposed rats demonstrated a sustained, increased expression of a number of genes implicated in the innate and adaptive immune responses (74). Chronic lung cell damage, and in particular apoptosis, when combined with ineffective phagocytic removal of apoptosed cell bodies (37) may result in the generation of neoantigens (for example, nucleosomes or DNA fragments; ref. 75), peptides (76), and autoantibodies. Both CD4 ${ }^{+}$ and $\mathrm{CD}^{+} \mathrm{T}$ lymphocytes are abundantly present in emphysematous lungs $(30,42,77)$, as are B cells, arranged also in lymph follicles $(40,42)$. Comparisons can be drawn with rheumatoid arthritis (28), another slowly progressive inflammatory disease wherein B cell follicles are prevalent. In addition, tobacco anti-idiotypic antibodies have been identified in serum from smokers (78) and antielastin antibodies in serum from patients with emphysema (79).

Based on studies designed to destroy tumor vessel endothelium by immunizing mice with xenogeneic HUVECs (80), we immunized rats with HUVECs with the intent of attacking the pulmonary endothelium (44). In this model, intraperitoneal injection of endothelial cells causes emphysema, activation of MMP-2 and -9 , and generation of anti-endothelial cell antibodies. This model provides proof of concept for an autoimmune mechanism of endothelial cell apoptosis in the development of emphysema, because the emphysema can be passively transferred to naive animals following administration of either $\mathrm{CD}^{+} \mathrm{T}$ cells or serum from HUVEC-immunized rats. If detected in patients with emphysema, anti-endothelial cell antibodies conceivably could explain the loss of capillaries not only in the lung, but also in skeletal muscle, as well as the muscle wasting in patients with COPD-emphysema. Interestingly, HUVEC-immunized rats injected concomitantly with the TLR4 ligand lipid A are protected against lung cell apoptosis and do not develop emphysema (81). Reports that smoking decreases the number of lung tissue dendritic cells (82) but also that smoking induces an increase in the number of airway dendritic cells (83) have been published. In addition, smoking causes TLR4-dependent dendritic cell activation (72).

At present there are no data that provide solid evidence in support of an autoimmune pathogenesis of human emphysema, but at least we can see the horizon, and the evidence seekers are armed with criteria consistent with modified Koch's postulates for autoimmune diseases (84): namely, that emphysema develops in the presence of pathogenic $\mathrm{CD} 4^{+} \mathrm{T}$ cells, that adoptive transfer of $\mathrm{CD} 4^{+} \mathrm{T}$ cells results in emphysema, and that emphysema does not occur in the absence of $\mathrm{CD}^{+} \mathrm{T}$ cells (44). Although smoking has been identified as a risk factor for the development of autoimmune diseases, it is unknown whether smoking can generate anti-endothelial cell or anti-epithelial cell antibodies. Perhaps a productive search can follow the lead of arthritis research, for which antibodies against citrulinated proteins (which are highly specific for rheumatoid arthritis) have been found in almost every patient (85). Other aspects of the involvement of the immune system in the pathogenesis of emphysema can perhaps be examined in the setting of pulmonary capillaritis, a distinct interstitial reaction associated with diffuse alveolar hemorrhage (86). Clearly, the tools are available to pursue and explore the hypothesis of "autoimmune emphysema." 


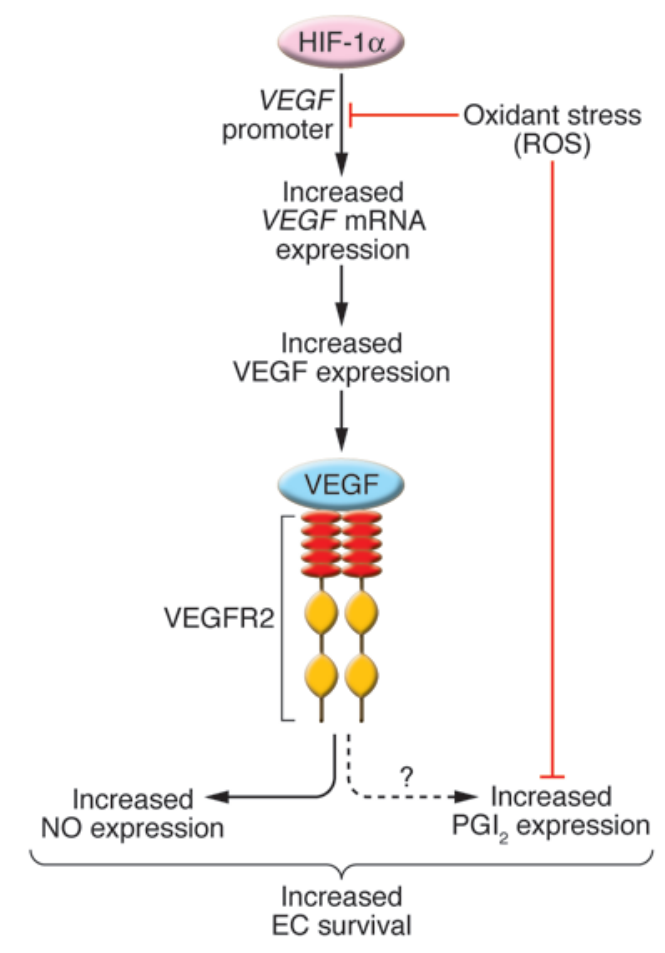

In two different mouse strains with lung-specific overexpression of IL-4 (Th2-prone BALB/c and Th1-prone C57BL/ 6 mice), only the Th1-prone C57BL/6 strain develops an inflammatory emphysematous and fibrotic phenotype (87). In a remarkable series of experiments, the authors showed that the effects of IL-4 overexpression were not due to overexpression of Th2 cytokines, but that IL- 4 overexpression affected lung TGF- $\beta 1$ and AAT levels and reduced adenosine deaminase activity, leading to a fold increase in adenosine levels. Interestingly, adenosine deaminasedeficient mouse lungs show inflammation and alveolar space enlargement (88), adenosine causes endothelial cell apoptosis (89), and indeed the authors could demonstrate that treatment with adenosine deaminase reduced inflammation, emphysema, and fibrosis in the IL-4-overexpressing C57BL/6 mice (87). Thus, this transgenic mouse study ties together genetic susceptibility, immune response, and lung pathology. High expression of IL-4 has indeed been reported in human emphysema lungs (90). Whether adenosine deaminase levels or activity are increased in human emphysema is unknown.

\section{No VEGF, no growth - only death}

Although it is premature to delineate a particular molecular sequence of events that begins with some form of mitochondrial stress and ends with death of alveolar septal structure cells, collectively the data indicate that oxidant stress occurs and that there is indeed proteolysis and apoptosis. Both epithelial cells and endothelial cells die, and their apoptosis has been demonstrated in human and animal lungs $(34,62,91-93)$. The loss of alveolar capillary endothelial cells and of small capillaries (94) de facto makes emphysema also a vascular disease (95-99). However, whether the loss of the structure-supporting matrix is primary and begets epithelial cell death, which in turn leads to endothelial cell demise, remains unresolved. The pleiotropic "arch-growth factor," VEGF (its role in the lung has been recently reviewed;

\section{Figure 4}

One pathway likely involved in lung cell structure maintenance. VEGF gene expression is controlled by hypoxia-inducible factor $1 \alpha(\mathrm{HIF}-1 \alpha)$. In endothelial cells, synthesis of prostacyclin $\left(\mathrm{PGI}_{2}\right)$ and NO is one outcome of VEGFR activation. Reactive oxygen species can damage the promoter region of the VEGF gene and thus impair VEGF transcription. Activation of VEGFR2 induces $\mathrm{NO}$ production. $\mathrm{NO}$ and $\mathrm{PGI}_{2}$ promote endothelial cell survival. While it is known that VEGFR2 activation promotes NO production, the link between VEGFR2 activation and $\mathrm{PGI}_{2}$ synthesis still needs to be established.

ref. 100), is normally abundantly expressed in the adult lung tissue. Its receptor, VEGFR2 (also known as KDR), is, at least in the rat (101), expressed on both epithelial and endothelial cells, and VEGFR blockade (62) or conditional knockout of the VEGF gene (102) causes lung cell apoptosis and emphysema. Both VEGF ligand and VEGFR expression are reduced in human emphysematous lungs (92). As in the islet cell apparatus of the pancreas (103) and in the glomeruli of the kidney (104), alveolar septal endothelial cells may vitally depend on paracrine and autocrine (105) VEGF survival signals and may be vulnerable to VEGFR blockade or VEGF withdrawal (106). In addition, VEGF signaling leads to endothelial prostacyclin synthesis (Figure 4), and loss of prostacyclin synthase expression in the endothelial monolayers of small pulmonary arteries in emphysematous lungs and decreased prostacyclin synthesis (107) may put these cells into double jeopardy and may remove yet another lung capillary endothelial cell survival factor. Effective transcription of the VEGF gene may be hampered by oxidative DNA damage of the hypoxia-inducible factor $1 \alpha(\mathrm{HIF}-1 \alpha)$ response element of the VEGF promoter (108). Given the bombardment of the cells in smokers' lungs with oxidants, one could easily embrace a VEGF/endothelial cell-centric hypothesis of emphysema. However, we should acknowledge that while this section focuses on VEGF, other growth factors and signaling molecules also play a role in emphysema pathogenesis. Gene expression studies of lungs from patients with COPD (109) suggest that the cells in these end-stage lungs are fundamentally compromised because of impaired mitochondrial energy metabolism and impaired protein synthesis. The precise mechanisms of this metabolic synthetic failure are not understood, but posttranslational protein modifications and impaired transcription due to DNA damage come to mind.

\section{Cellular senescence}

In addition to outright cell death, we have to consider a role of cellular senescence (not to be confused with the normal aging process of the lung) - a process of replication fatigue - in emphysema (110), as there is mounting evidence that cellular senescence may contribute to emphysema pathogenesis. Sato et al. (111) showed that cigarette smoke exposure caused airspace enlargement in senescence marker protein-30-knockout (SMP30-knockout) mice (SMP30 is a multifactorial protein that protects against aging), and Tsuji et al. (39) demonstrated overexpression of the cellular senescence marker p16 and telomere shortening in alveolar type II cells and endothelial cells in the lungs of smokers with emphysema. Cigarette smoke extract induces cellular senescence of normal human fibroblasts (38). Of interest, senescent cells may contribute to the chronicity of inflammation. Senescent cells stop synthesizing proteins, and this aspect may be shared by conditions of starvation, which, 
likely by affecting protein synthesis, causes potentially reversible emphysema (112). Results of early studies by Massaro and colleagues in rats (113) are now reflected in the radiographically documented emphysema in patients with anorexia (114). Recent data indicate that starvation causes lung cell apoptosis (112), but starvation-induced emphysema was not accompanied by inflammation; neither was the alveolar septum destruction caused by intratracheal instillation of active caspase-3 (29). Whether this caspase-3-induced emphysema model also displays features of impaired phagocytosis of apoptosed cell bodies is unknown.

\section{Can there be repair?}

Lung repair and restitution of function are the holy grail of modern lung biology. At present, the winning arguments are with those who maintain: it can't be done, it won't work. The loss of the densely woven, well-organized network of collagen and elastin fibers (Figure 3) on which alveolar epithelial and endothelial cell sit may be critical and repair-limiting (115). In addition, the damaged lung may "remember" the accumulated inflicted injury. For example, in damaged skin, colocalization of elastin and the oxidative stress marker 4-hydroxy-nonenal has been identified, as well as colocalization of elastin and the cell toxin acrolein (116). Although acrolein can upregulate endothelial cell heme oxygenase-1 (117), it is also one of the most chemically reactive aldehydes inhaled with cigarette smoke (118), and lysyl-acroleinated proteins have been detected in plasma samples from smokers (119). Acrolein-DNA adducts may prevent the return to normal lung cell function; so may a smoking-induced imbalance between histone deacetylation and acetylation $(120,121)$.

What about the idea that the bone marrow can repair the lung? Indeed, small numbers of bone marrow-derived cells have been identified in the adult human lung (122). For bone marrowderived precursor cells to repair the injured lung, several conditions must be met: (a) precursor cells must be available in the marrow; (b) precursor cells must be mobilized from the bone marrow and traffic to the site of injury; and (c) the precursor cells must be integrated into the existing lung structure, divide, and differentiate. It may be possible to examine all of these steps in the adult and even the senile mouse. But in emphysema patients, these mechanisms may be impaired. In the human long-term smoker, the marrow precursor cell pool may be reduced (123) and VEGF-dependent precursor cell mobilization (124) may be impaired. At present the issue of hematopoietic cells repopulating the lung after injury remains controversial $(125, \mathrm{~S} 1)$ (see Supplemental References; supplemental material available online with this article; doi:10.1172/ JCI31811DS1). Of note, inflammatory lipid mediators, like leukotriene B4, may control the proliferation of some stem cell populations (S2), again perhaps pointing toward a potentially homeostatic role of some elements of the inflammatory repertoire. Most likely, chronic cigarette smoking alters the gene expression pattern of all different cell types of the lung (S3, S4).

Hogan's group investigated the contribution of ciliated cells in the repair of naphthalene-injured airways and found that ciliated cells do not proliferate or transdifferentiate as part of the repair process (S5). Side population cells have been found in the rat lung (S6), but their role in lung repair is unclear.

\section{Conclusions, further questions, and outlook}

Emphysema research is going strong and going forward. Controversial issues ranging from how to measure airspace enlargement accurately (S7) and how to define aging of the lung (S8) are being raised and debated.

Transgenic mouse studies have uncovered a few of the facets and inner workings of the lung structure maintenance program (S9); however, we do not understand how so many different genetic manipulations result in emphysema. This maintenance program, so we believe, has a purpose and is designed for homeostasis - balancing cell loss and cell regeneration. The complexity of this program is presently beyond our comprehension, as new components of the program are being discovered on an ongoing basis. The maintenance of the structure is not only jeopardized by a multitude of proteases; not only can the defense against oxidants be overwhelmed by ceramide (73), but myeloperoxidase-derived products such as acrolein (S10) may modify proteins and DNA, thus generating a permanent record of environmental and endogenous stress. Cell death, now accepted as a cause of emphysema, may occur in the lung in a variety of scenarios when stress pathways have been activated beyond a point of no return. Where exactly is this point? If intervention with the goal to prevent cell death were feasible, would it prevent or treat an autoimmune disease component but lead to cancer?

Breakdown of structure maintenance may also lead to, or may be associated with, repair failure. Conceptually, the failure to repair the adult lung is caused by an impairment of resident lung stem cells, the impaired mobilization of precursor cells from the bone marrow (S11), or a failure of integration of adequately mobilized bone marrow-derived precursors (S12) into the residual lung tissue because of a permanent loss of the scaffold.

Intuitively, prevention of emphysema (S13) or perhaps disease arrest (S14) appears to be a more achievable goal than reversal of often massive lung structure damage. The impact of diet on COPD has been considered (S15). The Mediterranean diet, in particular the consumption of olive oil, may protect DNA against oxidative damage (S16), resveratrol may inhibit inflammatory cytokine release (S17), and fish consumption may limit the lung damage caused by smoking (S18). Dietary manipulations have successfully been tested in rodent models (S19), and drugs such as statins (S20) also show a protective effect in COPD patients (S21).

In the aggregate, the field of COPD and emphysema research has been very much energized in the last decade. A spirit of enterprise and hope for improving the lives of millions of patients suffering from this disease has emerged in both the clinic and the laboratory. Patients with smoking-related COPD/emphysema and patients with emphysema of unclear etiology alike are expected to benefit from this hopeful change. Future research will surely increase our understanding of both the cellular and molecular mechanisms at work during normal lung function and under conditions in which the lung is exposed to environmental stress.

\section{Acknowledgments}

This work was supported by NIH grant R01 HL66554, a Hart Family Endowed Chair in Emphysema Research, and the Bixler COPD Foundation. The critical reading of this manuscript by Mark Nicolls, Stanford Medical School, is gratefully acknowledged.

Address correspondence to: Norbert F. Voelkel, Victoria Johnson Center for Emphysema Research, School of Medicine, Virginia Commonwealth University, 1101 E. Marshall St. Sanger Hall 7024, Richmond, Virginia 23298, USA. Phone: (804) 628-9615; Fax: (804) 628-0325; E-mail: nvoelkel@mcvh-vcu.edu. 
1. Fulton, J.F. 1930. Selected readings in the history of physiology. Charles C. Thomas. Springfield, Illinois, USA. 307-315

2. Snider, G.L., Kleinerman, J., Thurlbeck, W.M., and Bengali, Z.H. 1985. The definition of emphysema. Am. Rev. Respir. Dis. 132:182-185.

3. Laennec, R.T. 1819. De auscultation médiate; ou, Traité du diagnostic del maladies des poumons et du coeur. Brosson et Chaude. Paris, France.

4. Laennec, R.T. 1834. A treatise on the diseases of the chest. Longman. London, United Kingdom.

5. Filley, G.F. 1967. Emphysema and chronic bronchitis: clinical manifestations and their physiologic significance. Med. Clin. North Am. 51:283-292.

6. Sahebjami, H. 1992. Emphysema-like changes in HIV. Ann. Intern. Med. 116:876.

7. Tuder, R.M., and Voelkel, N.F. 2002. The pathobiology of chronic bronchitis and emphysema. In Chronic obstructive lung diseases. N.F. Voelkel and W. MacNee, editors. B.C. Decker. London, United Kingdom. 90-113.

8. Finkelstein, R., et al. 1995. Morphometry of small airways in smokers and its relationship to emphysema type and hyperresponsiveness. Am. J. Respir. Crit. Care Med. 152:267-276.

9. Cote, C., Zilberberg, M.D., Mody, S.H., Dordelly, L.J., and Celli, B. 2007. Haemoglobin level and its clinical impact in a cohort of patients with COPD. Eur. Respir. J. 29:923-929.

10. Engelen, M.P., Schols, A.M., Lamers, R.J., and Wouters, E.F. 1999. Different patterns of chronic tissue wasting among patients with chronic obstructive pulmonary disease. Clin. Nutr. 18:275-280.

11. Sabit, R., et al. 2007. Arterial stiffness and osteoporosis in chronic obstructive pulmonary disease. Am. J. Respir. Crit. Care Med. 175:1259-1265.

12. Celli, B.R. 2006. Chronic obstructive pulmonary disease: from unjustified nihilism to evidencebased optimism. Proc. Am. Thorac. Soc. 3:58-65.

13. Murray, C.J., and Lopez, A.D. 1997. Alternative projections of mortality and disability by cause 1990-2020: Global Burden of Disease Study. Lancet. 349:1498-1504.

14. Sullivan, S.D., Ramsey, S.D., and Lee, T.A. 2000. The economic burden of COPD. Chest. 117:5S-9S.

15. Symposium of Emphysema and the "Chronic Bronchitis” Syndrome. 1959. Am. Rev. Respir. Dis. 80:1-213.

16. Fletcher, C., and Peto, R. 1977. The natural history of chronic airflow obstruction. Br. Med.J. 1:1645-1648.

17. Abbey, D.E., et al. 1998. Long-term particulate and other air pollutants and lung function in nonsmokers. Am. J. Respir. Crit. Care Med. 158:289-298.

18. Jimenez, L.A., et al. 2000. Activation of NF-kappaB by $\mathrm{PM}(10)$ occurs via an iron-mediated mechanism in the absence of IkappaB degradation. Toxicol. Appl. Pharmacol. 166:101-110.

19. Karakatsani, A., et al. 2003. Air pollution in relation to manifestations of chronic pulmonary disease: a nested case-control study in Athens, Greece. Eur. J. Epidemiol. 18:45-53.

20. Joos, L., Pare, P.D., and Sandford, A.J. 2002. Genetic risk factors. In Chronic obstructive lung diseases. $\mathrm{N}$. Voelkel and W. MacNee, editors. B.C. Decker. London, United Kingdom. 56-64.

21. Ferrarotti, I., et al. 2003. Tumour necrosis factor family genes in a phenotype of COPD associated with emphysema. Eur. Respir. J. 21:444-449.

22. Demeo, D.L., et al. 2006. The SERPINE2 gene is associated with chronic obstructive pulmonary disease. Am. J. Hum. Genet. 78:253-264.

23. Ito, I., et al. 2005. Matrix metalloproteinase-9 promoter polymorphism associated with upper lung dominant emphysema. Am. J. Respir. Crit. Care Med. 172:1378-1382.

24. Gauldie, J., et al. 2006. Smad3 signaling involved in pulmonary fibrosis and emphysema. Proc. Am. Thorac. Soc. 3:696-702.
25. Jankowich, M.D., Polsky, M., Klein, M., and Rounds, S. 2007. Heterogeneity in combined pulmonary fibrosis and emphysema. Respiration. 730:1-7.

26. Gross, P., Babyak, M.A., Tolker, E., and Kaschak, M. 1964. Enzymatically produced pulmonary emphysema: a preliminary report. J. Occup. Med. 6:481-484.

27. Eriksson, S. 1964. Pulmonary emphysema and alpha1-antitrypsin deficiency. Acta Med. Scand. 175:197-205.

28. Agusti, A., MacNee, W., Donaldson, K., and Cosio, M. 2003. Hypothesis: does COPD have an autoimmune component? Thorax. 58:832-834.

29. Aoshiba, K., Yokohori, N., and Nagai, A. 2003. Alveolar wall apoptosis causes lung destruction and emphysematous changes. Am. J. Respir. Cell Mol. Biol. 28:555-562.

30. Grumelli, S., et al. 2004. An immune basis for lung parenchymal destruction in chronic obstructive pulmonary disease and emphysema. PLoS Med. 1:e8.

31. Zhang, X., Shan, P., Jiang, G., Cohn, L., and Lee, P.J. 2006. Toll-like receptor 4 deficiency causes pulmonary emphysema. J. Clin. Invest. 116:3050-3059.

32. Morris, D.G., and Sheppard, D. 2006. Pulmonary emphysema: when more is less. Physiology (Bethesda). 21:396-403.

33. Yoshida, T., and Tuder, R.M. 2007. Pathobiology of cigarette smoke-induced chronic obstructive pulmonary disease. Physiol. Rev. 87:1047-1082.

34. Calabrese, F., et al. 2005. Marked alveolar apoptosis/ proliferation imbalance in end-stage emphysema. Respir. Res. 6:14

35. Kanazawa, H., and Yoshikawa, J. 2005. Elevated oxidative stress and reciprocal reduction of vascular endothelial growth factor levels with severity of COPD. Chest. 128:3191-3197.

36. Tuder, R.M., et al. 2003. Oxidative stress and apoptosis interact and cause emphysema due to vascular endothelial growth factor receptor blockade. Am. J. Respir. Cell Mol. Biol. 29:88-97.

37. Vandivier, R.W., Henson, P.M., and Douglas, I.S. 2006. Burying the dead: the impact of failed apoptotic cell removal (efferocytosis) on chronic inflammatory lung disease. Chest. 129:1673-1682.

38. Nyunoya, T., et al. 2006. Cigarette smoke induces cellular senescence. Am. J. Respir. Cell Mol. Biol. 35:681-688.

39. Tsuji, T., Aoshiba, K., and Nagai, A. 2006. Alveolar cell senescence in patients with pulmonary emphysema. Am. J. Respir. Crit. Care Med. 174:886-893.

40. Taraseviciene-Stewart, L., et al. 2006. Is alveolar destruction and emphysema in chronic obstructive pulmonary disease an immune disease? Proc. Am. Thorac. Soc. 3:687-690.

41. Voelkel, N.F. 2002. Historical overview of emphysema. In Chronic obstructive lung diseases. N.F. Voelkel and W. MacNee, editors. B.C. Decker. London, United Kingdom. 1-6.

42. Hogg, J.C., et al. 2004. The nature of small-airway obstruction in chronic obstructive pulmonary disease. N. Engl. J. Med. 350:2645-2653.

43. Mercer, B.A., Kolesnikova, N., Sonett, J., and D’Armiento, J. 2004. Extracellular regulated kinase/mitogen activated protein kinase is upregulated in pulmonary emphysema and mediates matrix metalloproteinase- 1 induction by cigarette smoke. J. Biol. Chem. 279:17690-17696.

44. Taraseviciene-Stewart, L., et al. 2005. An animal model of autoimmune emphysema. Am. J. Respir. Crit. Care Med. 171:734-742.

45. Houghton, A.M., et al. 2006. Elastin fragments drive disease progression in a murine model of emphysema. J. Clin. Invest. 116:753-759.

46. Ofulue, A.F., and Ko, M. 1999. Effects of depletion of neutrophils or macrophages on development of cigarette smoke-induced emphysema. Am. J. Physiol. 277:L97-L105.

47. Hautamaki, R.D., Kobayashi, D.K., Senior, R.M., and Shapiro, S.D. 1997. Requirement for macrophage elastase for cigarette smoke-induced emphysema in mice. Science. 277:2002-2004.

48. Eidelman, D., et al. 1990. Cellularity of the alveolar walls in smokers and its relation to alveolar destruction. Functional implications. Am. Rev. Respir. Dis. 141:1547-1552.

49. Finkelstein, R., Fraser, R.S., Ghezzo, H., and Cosio, M.G. 1995. Alveolar inflammation and its relation to emphysema in smokers. Am. J. Respir. Crit. Care Med. 152:1666-1672.

50. Owen, C.A. 2005. Proteinases and oxidants as targets in the treatment of chronic obstructive pulmonary disease. Proc. Am. Thorac. Soc. 2:373-385.

51. Fischer, U., Janicke, R.U., and Schulze-Osthoff, K. 2003. Many cuts to ruin: a comprehensive update of caspase substrates. Cell Death Differ. 10:76-100.

52. Elkington, P.T., and Friedland, J.S. 2006. Matrix metalloproteinases in destructive pulmonary pathology. Thorax. 61:259-266.

53. Greenlee, K.J., Werb, Z., and Kheradmand, F. 2007. Matrix metalloproteinases in lung: multiple, multifarious, and multifaceted. Physiol. Rev. 87:69-98.

54. D’Armiento, J., Dalal, S.S., Okada, Y., Berg, R.A., and Chada, K. 1992. Collagenase expression in the lungs of transgenic mice causes pulmonary emphysema. Cell. 71:955-961.

55. Foronjy, R.F., Okada, Y., Cole, R., and D'Armiento, J. 2003. Progressive adult-onset emphysema in transgenic mice expressing human MMP-1 in the lung. Am. J. Physiol. Lung Cell Mol. Physiol. 284:L727-L737.

56. Segura-Valdez, L., et al. 2000. Upregulation of gelatinases A and B, collagenases 1 and 2 , and increased parenchymal cell death in COPD. Chest. 117:684-694

57. Stone, P.J., et al. 1995. Elastin and collagen degradation products in urine of patients with cystic fibrosis. Am. J. Respir. Crit. Care Med. 152:157-162.

58. Wright, J.L., and Churg, A. 1995. Smoke-induced emphysema in guinea pigs is associated with morphometric evidence of collagen breakdown and repair. Am. J. Physiol. 268:L17-L20.

59. Zheng, T., et al. 2005. Role of cathepsin S-dependent epithelial cell apoptosis in IFN-gammainduced alveolar remodeling and pulmonary emphysema. J. Immunol. 174:8106-8115.

60. Wang, B., et al. 2006. Cathepsin S controls angiogenesis and tumor growth via matrix-derived angiogenic factors. J. Biol. Chem. 281:6020-6029.

61. Demura, Y., Taraseviciene-Stewart, L., Scerbavicius, R., Tuder, R.M., and Voelkel, N.F. 2004. N-acetylcysteine treatment protects against VEGF-receptor blockade-related emphysema. COPD. 1:25-32.

62. Kasahara, Y., et al. 2000. Inhibition of VEGF receptors causes lung cell apoptosis and emphysema. J. Clin. Invest. 106:1311-1319.

63. Petrache, I., et al. 2006. A novel antiapoptotic role for alpha1-antitrypsin in the prevention of pulmonary emphysema. Am. J. Respir. Crit. Care Med. 173:1222-1228

64. Tuder, R.M., Petrache, I., Elias, J.A., Voelkel, N.F., and Henson, P.M. 2003. Apoptosis and emphysema: the missing link. Am. J. Respir. Cell Mol. Biol. 28:551-554.

65. Churg, A., Wang, R.D., Xie, C., and Wright, J.L. 2003. alpha-1-Antitrypsin ameliorates cigarette smoke-induced emphysema in the mouse. Am.J. Respir. Crit. Care Med. 168:199-207.

66. Petrache, I., et al. 2006. $\alpha$-1 Antitrypsin inhibits caspase-3 activity, preventing lung endothelial cell apoptosis. Am. J. Pathol. 169:1155-1166.

67. Lewis, E.C., Shapiro, L., Bowers, O.J., and Dinarello, C.A. 2005. Alpha1-antitrypsin monotherapy prolongs islet allograft survival in mice. Proc. Natl. Acad. Sci. U. S. A. 102:12153-12158.

68. Fujita, M., et al. 2001. Overexpression of tumor necrosis factor-alpha produces an increase in lung volumes and pulmonary hypertension. Am.J. Physiol. 
Lung Cell Mol. Physiol. 280:L39-L49.

69. Singh, A., et al. 2006. Glutathione peroxidase 2, the major cigarette smoke-inducible isoform of GPX in lungs, is regulated by Nrf2. Am. J. Respir. Cell Mol. Biol. 35:639-650.

70. Rangasamy, T., et al. 2004. Genetic ablation of Nrf2 enhances susceptibility to cigarette smoke-induced emphysema in mice. J. Clin. Invest. 114:1248-1259.

71. Johnson, G.B., Brunn, G.J., Kodaira, Y., and Platt, J.L. 2002. Receptor-mediated monitoring of tissue well-being via detection of soluble heparan sulfate by Toll-like receptor 4. J. Immunol. 168:5233-5239.

72. Maes, T., et al. 2006. Murine TLR4 is implicated in cigarette smoke-induced pulmonary inflammation. Int. Arch. Allergy Immunol. 141:354-368.

73. Petrache, I., et al. 2005. Ceramide upregulation causes pulmonary cell apoptosis and emphysemalike disease in mice. Nat. Med. 11:491-498.

74. Gebel, S., et al. 2006. The kinetics of transcriptomic changes induced by cigarette smoke in rat lungs reveals a specific program of defense, inflammation, and circadian clock gene expression. Toxicol. Sci. 93:422-431.

75. Pisetsky, D.S. 2007. The role of nuclear macromolecules in innate immunity. Proc. Am. Thorac. Soc. 4:258-262.

76. Mahoney, J.A., and Rosen, A. 2005. Apoptosis and autoimmunity. Curr. Opin. Immunol. 17:583-588.

77. Sullivan, A.K., et al. 2005. Oligoclonal CD4+ T cells in the lungs of patients with severe emphysema. Am. J. Respir. Crit. Care Med. 172:590-596.

78. Koethe, S.M., Kuhnmuench, J.R., and Becker, C.G. 2000. Neutrophil priming by cigarette smoke condensate and a tobacco anti-idiotypic antibody. Am J. Pathol. 157:1735-1743.

79. Lee, S.H., et al. 2007. Antielastin autoimmunity in tobacco smoking-induced emphysema. Nat. Med. 13:567-569.

80. Wei, Y.Q., et al. 2000. Immunotherapy of tumors with xenogeneic endothelial cells as a vaccine. Nat. Med. 6:1160-1166.

81. Taraseviciene-Stewart, L., et al. 2006. Is alveolar destruction and emphysema in chronic obstructive pulmonary disease an immune disease? Proc. Am. Thorac. Soc. 3:687-690.

82. Robbins, C.S., et al. 2004. Cigarette smoke decreases pulmonary dendritic cells and impacts antiviral immune responsiveness. Am. J. Respir. Cell Mol. Biol. 30:202-211.

83. Soler, P., Moreau, A., Basset, F., and Hance, A.J. 1989. Cigarette smoking-induced changes in the number and differentiated state of pulmonary dendritic cells/Langerhans cells. Am. Rev. Respir. Dis. 139:1112-1117.

84. Rose, N.R., and Bona, C. 1993. Defining criteria for autoimmune diseases(Witebsky's postulates revisited). Immunol. Today. 14:426-430.

85. Peene, I., et al. 2004. History and diagnostic value of antibodies to citrullinated proteins in rheumatoid arthritis. Int. J. Immunopathol. Pharmacol. 17:107-116

86. Hunt, D.P., et al. 2006. Pulmonary capillaritis and its relationship to development of emphysema in hypocomplementaemic urticarial vasculitis syndrome. Sarcoidosis Vasc. Diffuse Lung Dis. 23:70-72.

87. Ma, B., et al. 2006. Adenosine metabolism and murine strain-specific IL-4-induced inflammation, emphysema, and fibrosis. J. Clin. Invest. 116:1274-1283.

88. Blackburn, M.R., et al. 2000. Metabolic conse- quences of adenosine deaminase deficiency in mice are associated with defects in alveogenesis, pulmonary inflammation, and airway obstruction. J. Exp. Med. 192:159-170.

89. Harrington, E.O., Smeglin, A., Parks, N., Newton, J., and Rounds, S. 2000. Adenosine induces endothelial apoptosis by activating protein tyrosine phosphatase: a possible role of p38alpha. Am. J. Physiol. Lung Cell Mol. Physiol. 279:L733-L742.

90. Jeffery, P.K. 1999. Differences and similarities between chronic obstructive pulmonary disease and asthma. Clin. Exp. Allergy. 29(Suppl. 2):14-26.

91. Hodge, S., Hodge, G., Holmes, M., and Reynolds, P.N. 2005. Increased airway epithelial and T-cell apoptosis in COPD remains despite smoking cessation. Eur. Respir. J. 25:447-454.

92. Kasahara, Y., et al. 2001. Endothelial cell death and decreased expression of vascular endothelial growth factor and vascular endothelial growth factor receptor 2 in emphysema. Am. J. Respir. Crit. Care Med. 163:737-744.

93. Zhong, C.Y., Zhou, Y.M., Joad, J.P., and Pinkerton, K.E. 2006. Environmental tobacco smoke suppresses nuclear factor-kappaB signaling to increase apoptosis in infant monkey lungs. Am. J. Respir. Crit. Care Med. 174:428-436.

94. Liebow, A.A. 1959. Pulmonary emphysema with special reference to vascular changes. Am. Rev. Respir. Dis. 80:67-93.

95. Santos, S., et al. 2002. Characterization of pulmonary vascular remodelling in smokers and patients with mild COPD. Eur. Respir. J. 19:632-638.

96. Shapiro, S.D. 2000. Vascular atrophy and VEGFR-2 signaling: old theories of pulmonary emphysema meet new data. J. Clin. Invest. 106:1309-1310.

97. Voelkel, N., and Taraseviciene-Stewart, L. 2005 Emphysema: an autoimmune vascular disease? Proc. Am. Thorac. Soc. 2:23-25.

98. Wright, J.L., Tai, H., and Churg, A. 2006. Vasoactive mediators and pulmonary hypertension after cigarette smoke exposure in the guinea pig. J. Appl. Physiol. 100:672-678.

99. Yamato, H., Sun, J.P., Churg, A., and Wright, J.L. 1996. Cigarette smoke-induced emphysema in guinea pigs is associated with diffusely decreased capillary density and capillary narrowing. Lab. Invest. 75:211-219.

100.Voelkel, N.F., Vandivier, R.W., and Tuder, R.M. 2006. Vascular endothelial growth factor in the lung. Am. J. Physiol. Lung Cell Mol. Physiol. 290:L209-L221.

101.Fehrenbach, H., Kasper, M., Haase, M., Schuh, D., and Muller, M. 1999. Differential immunolocalization of VEGF in rat and human adult lung, and in experimental rat lung fibrosis: light, fluorescence, and electron microscopy. Anat. Rec. 254:61-73.

102.Tang, K., Rossiter, H.B., Wagner, P.D., and Breen, E.C. 2004. Lung-targeted VEGF inactivation leads to an emphysema phenotype in mice.J. Appl. Physiol. 97:1559-1566.

103. Lammert, E., et al. 2003. Role of VEGF-A in vascularization of pancreatic islets. Curr. Biol. 13:1070-1074.

104.Eremina, V., et al. 2006. Vascular endothelial growth factor a signaling in the podocyte-endothelial compartment is required for mesangial cell migration and survival. J. Am. Soc. Nephrol. 17:724-735.

105. Lee, S., et al. 2007. Autocrine VEGF signaling is required for vascular homeostasis. Cell. 130:691-703.

106.Stevens, T., Kasper, M., Cool, C., and Voelkel, N. 2005. Pulmonary circulation and pulmonary hypertension. In Endothelial cells in bealth and disease.
W.C. Aird, editor. Taylor \& Francis Group. Boca Raton, Florida, USA. 417-438.

107. Nana-Sinkam, P.S., et al. 2007. Prostacyclin prevents pulmonary endothelial cell apoptosis induced by cigarette smoke. Am. J. Respir. Crit. Care Med. 175:676-685.

108.Ziel, K.A., et al. 2005. Oxidants in signal transduction: impact on DNA integrity and gene expression. FASEBJ. 19:387-394.

109.Golpon, H.A., et al. 2004. Emphysema lung tissue gene expression profiling. Am. J. Respir. Cell Mol. Biol. 31:595-600.

110.Takahashi, A., et al. 2006. Mitogenic signalling and the p16INK4a-Rb pathway cooperate to enforce irreversible cellular senescence. Nat. Cell Biol. 8:1291-1297.

111.Sato, T., et al. 2006. Senescence marker protein-30 protects mice lungs from oxidative stress, aging, and smoking. Am. J. Respir. Crit Care Med. 174:530-537.

112. Massaro, D., Massaro, G.D., Baras, A., Hoffman, E.P., and Clerch, L.B. 2004. Calorie-related rapid onset of alveolar loss, regeneration, and changes in mouse lung gene expression. Am. J. Physiol Lung Cell Mol. Physiol. 286:L896-L906.

113.Thet, L.A., Delaney, M.D., Gregorio, C.A., and Massaro, D. 1977. Protein metabolism by rat lung: influence of fasting, glucose, and insulin. J. Appl. Physiol. 43:463-467.

114. Coxson, H.O., et al. 2004. Early emphysema in patients with anorexia nervosa. Am. J. Respir. Crit. Care Med. 170:748-752.

115.Shifren, A., and Mecham, R.P. 2006. The stumbling block in lung repair of emphysema: elastic fiber assembly. Proc. Am. Thorac. Soc. 3:428-433.

116. Tanaka, N., Tajima, S., Ishibashi, A., Uchida, K., and Shigematsu, T. 2001. Immunohistochemical detection of lipid peroxidation products, protein-bound acrolein and 4-hydroxynonenal protein adducts, in actinic elastosis of photodamaged skin. Arch. Dermatol. Res. 293:363-367.

117. Wu, C.C., et al. 2006. Upregulation of endothelial heme oxygenase- 1 expression through the activation of the JNK pathway by sublethal concentrations of acrolein. Toxicol. Appl. Pharmacol. 214:244-252.

118.Fujioka, K., and Shibamoto, T. 2006. Determination of toxic carbonyl compounds in cigarette smoke. Environ. Toxicol. 21:47-54.

119.Uchida, K., et al. 1998. Protein-bound acrolein: potential markers for oxidative stress. Proc. Natl. Acad. Sci. U. S. A. 95:4882-4887.

120.Ito, K., et al. 2005. Decreased histone deacetylase activity in chronic obstructive pulmonary disease. N. Engl. J. Med. 352:1967-1976.

121.Szulakowski, P., et al. 2006. The effect of smoking on the transcriptional regulation of lung inflammation in patients with chronic obstructive pulmonary disease. Am. J. Respir. Crit. Care Med. 174:41-50.

122.Suratt, B.T., et al. 2003. Human pulmonary chimerism after hematopoietic stem cell transplantation. Am. J. Respir. Crit. Care Med. 168:318-322.

123. Bonsignore, M.R., et al. 2006. Circulating CD34+ cells are decreased in chronic obstructive pulmonary disease. Proc. Am. Thorac. Soc. 3:537-538.

124.Hattori, K., et al. 2001. Vascular endothelial growth factor and angiopoietin-1 stimulate postnatal hematopoiesis by recruitment of vasculogenic and hematopoietic stem cells. J. Exp. Med. 193:1005-1014.

125.Kotton, D.N., and Fine, A. 2008. Lung stem cells. Cell Tissue Res. 331:145-156. 